\title{
Soy Matrix Drug Delivery Systems Obtained by Melt-Processing Techniques
}

\author{
Cláudia M. Vaz, ${ }^{*}, \dagger$ Patrick F. N. M. van Doeveren, ${ }^{\ddagger}$ Rui L. Reis, ${ }^{\dagger} \S$ and António M. Cunha ${ }^{\dagger}$ \\ Department of Polymer Engineering, University of Minho, Campus de Azurem, 4800-058 Guimarães, \\ Portugal, ATO, Agrotechnological Research Institute, PO Box 17, 6700 AA Wageningen, The Netherlands, \\ and 3B's Research Group-Biomaterials, Biodegradables and Biomimetics, University of Minho, \\ Campus de Gualtar, 4710-057 Braga, Portugal
}

Received February 12, 2003; Revised Manuscript Received July 14, 2003

\begin{abstract}
The aim of this study was to develop new soy protein drug delivery matrix systems by melt-processing techniques, namely, extrusion and injection moulding. The soy matrix systems with an encapsulated drug (theophylline, $\mathrm{TH}$ ) were previously compounded by extrusion performed at two different $\mathrm{pH}$ values, (i) $\mathrm{pH}$ $4\left(\mathrm{SIpD}_{\mathrm{tp}}\right)$ and (ii) $\mathrm{pH} 7\left(\mathrm{SID}_{\mathrm{tp}}\right)$, and further injection-moulded into a desired shape. During the extrusion process the matrixes $\mathrm{SID}_{\mathrm{tp}}$ were also cross-linked with glyoxal $\left(0.6 \mathrm{X}-\mathrm{SID}_{\mathrm{tp}}\right)$ and reinforced with a bioactive filler, hydroxylapatite $\left(\mathrm{SI}_{-}-\mathrm{HAD}_{\mathrm{tp}}\right)$. The obtained mouldings were used to study the drug-release mechanisms from the plastic soy- TH matrixes. In an isotonic saline solution (ISS) buffered at pH 5.0 (200 mM acetate buffer), the resulting release kinetics could be described using the Fick's second law of diffusion. Because the diffusion coefficients were found to be constant and the boundary conditions to be stationary, these systems are drug-diffusion controlled. Conversely, the dominant phenomena in an isotonic saline solution buffered at $\mathrm{pH} 7.4$ (200 mM Tris/HCl buffer) are more complex. In fact, because of the higher polymer solubility, the resulting matrix is time-variant. So, the drug release is affected by swelling, drug diffusion, and polymer dissolution, being faster when compared to ISS $-200 \mathrm{mM}$ acetate buffer, $\mathrm{pH}$ 5.0. The changes in the formulation composition affecting the correspondent release rates were also investigated. At $\mathrm{pH} 7.4$, increasing the cross-linking degree of the polymer matrix (via reaction with glyoxal or heat treatment) or decreasing the net charge (extruding at $\mathrm{pH}$ near its isoelectric point) led to lower release rates. The incorporation of ceramic filler caused the opposite effect. Because of the low solubility of the matrix at $\mathrm{pH}$ 5.0, no significant variations were detected with variations in the selected formulations. These systems, based on a nonstandard protein-based material, seem to be very promising to be used as carriers for drug delivery.
\end{abstract}

\section{Introduction}

The most conventional way to make matrix drug delivery systems is based on the compression of polymer-drug mixtures into a compact form (e.g., slabs and tablets). ${ }^{1-3}$ Alternatively, the drugs can be previously granulated with the polymer so that the drug particles are covered with a layer aiming at retarding the respective release process. ${ }^{4,5}$ In other studies, drugs have also been incorporated into the polymer granulates using techniques such as (i) solvent evaporation, ${ }^{6}$ (ii) polymer solution granulation, ${ }^{7}$ (iii) melt granulation, ${ }^{8}$ and (iv) sintering. ${ }^{9}$ The obtained granulates were then compressed into slabs or tablets. However, the release kinetics was found to be greatly dependent on the compaction properties of the polymer-drug granules. ${ }^{6-9}$ Other alternatives include the design of matrix drug delivery systems in which the drug particles are dispersed in a melted polymeric phase. A common example is the compression of drug-filled

\footnotetext{
* To whom correspondence should be addressed. Tel.: + 3140247 4839. Fax: + 3140244 7355. E-mail: c.m.vaz@tue.nl.

$\dagger$ University of Minho, Campus de Azurém.

* ATO, Agrotechnological Research Institute.

$\S$ University of Minho, Campus de Gualtar.
}

polymeric compounds above the melting point of the polymer 46 to form a solid part containing the drug. ${ }^{10-12}$ In this type of 47 device, the release kinetics is controlled by the polymer bulk 48 properties and not by the porosity of the system.

A less-frequent methodology is the encapsulation of a drug 50 into a polymer extrudate that will be subsequently shaped 51 in the final geometry by injection moulding. The major 52 advantages over the more-conventional above-described 53 methods are (i) continuity of the production process because 54 the different production steps (mixing, melting, homogeniz- 55 ing, and shaping) are carried out in a single equipment, (ii) 56 cost-effective process because the technique usually offers 57 high throughputs, low material loss, and excellent homoge- 58 neity, (iii) high geometrical freedom, (iv) environmental 59 friendliness because no organic solvent is used during the 60 processing stage, (v) possibility to work in clean room 61 conditions, and (vi) high versatility in terms of materials and 62 formulations. ${ }^{10,11,13-15}$

Following this last described approach, soy protein was chosen as the matrix former because of its high availability and biodegradability, ${ }^{16}$ good melt processability, ${ }^{17}$ high thermal stability, ${ }^{17}$ and noncytotoxicity. ${ }^{18}$ Its outstanding 7 48 5 1 2 53 4 5 6 10 8 9 60 1 62 
Table 1. Compositions of the Investigated Matrixes ${ }^{a}$

\begin{tabular}{|c|c|c|c|c|c|c|}
\hline & \multicolumn{6}{|c|}{ formulation } \\
\hline & $S I_{t p}$ & SID $t p$ & $0.6 \mathrm{X}-\mathrm{SID}_{\mathrm{tp}}$ & 24TT-SID $\mathrm{tp}^{b}$ & SIpD tp & $\mathrm{SI}-\mathrm{HAD}_{\mathrm{tp}}$ \\
\hline soy & 100 & 100 & 100 & 100 & 100 & 100 \\
\hline glycerol & 10 & 10 & 10 & 10 & 10 & 10 \\
\hline water & 30 & 30 & 30 & 30 & 30 & 30 \\
\hline glyoxal & & & 0.6 & & & \\
\hline theophylline & & 20 & 20 & 20 & 20 & 20 \\
\hline hydroxylapatite & & & & & & 30 \\
\hline $\mathrm{pH}$ & $\sim 7.0$ & $\sim 7.0$ & $\sim 7.0$ & $\sim 7.0$ & $\sim 4.0$ & $\sim 7.0$ \\
\hline free amine group content (\%) & & $97.6 \pm 0.5$ & $55.9 \pm 1.0$ & $72.2 \pm 1.1$ & & \\
\hline
\end{tabular}

${ }^{a}$ All quantities in parts/100 g protein (phg). Abbreviations: $S I_{\mathrm{tp}}$, thermoplastic soy matrix; $\mathrm{SID}_{\mathrm{tp}}$, thermoplastic soy matrix with encapsulated theophylline; $0.6 X-S I D_{t p}$, glyoxal cross-linked thermoplastic soy matrix with encapsulated theophylline; $24 T T-S I D_{t p}$, thermal-treated thermoplastic soy matrix with encapsulated theophylline; $S I p D_{t p}$, thermoplastic soy matrix with encapsulated theophylline extruded at $\mathrm{pH} 4$; SI-HAD $\mathrm{D}_{\mathrm{tp}}$, hydroxylapatite reinforced thermoplastic soy matrix with encapsulated theophylline. ${ }^{b}$ Subjected to thermal treatment, $24 \mathrm{hrs} / 80^{\circ} \mathrm{C}$.

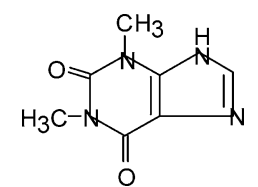

Figure 1. Chemical structure of theophylline anhydrous $(\mathrm{TH}$, $\mathrm{C}_{7} \mathrm{H}_{8} \mathrm{~N}_{4} \mathrm{O}_{2}$ ).

feasibility has been established by a variety of applications in the polymer, food, and agriculture fields. ${ }^{19-21}$ Although it is also used as a cosmetic aid ${ }^{22}$ and was proposed to be used in the biomedical field, ${ }^{23,24}$ no applications have been, to our knowledge, proposed on what concerns to the use of soy for the production of melt-extruded or injection-moulded drug/matrix compounds.

Therefore, this work was developed with the objective to explore the possibility to encapsulate a drug into a soy matrix by melt extrusion and subsequently study its suitability to be used as a drug delivery system. The release behavior of the obtained devices was investigated for a range of formulations to evaluate the effect of parameters such as the cross-linking degree, the matrix net charge, and the presence of bonelike ceramic reinforcements.

\section{Experimental Section}

2.1. Materials. The following materials were used as received from the manufacturers: soy protein isolate (amorphous, $83.4 \%$ protein w/w on dry basis, Loders Crocklaan BV, The Netherlands), glycerol, glyoxal (40\% v/v aqueous solution), o-phthaldialdehyde (OPA, Sigma-Aldrich Chemie $\mathrm{BV}$, Zwijndrecht, The Netherlands), and theophylline anhydrous ( $\mathrm{TH}, \mathrm{C}_{7} \mathrm{H}_{8} \mathrm{~N}_{4} \mathrm{O}_{2}, M_{\mathrm{w}}=180.2 \mathrm{~g} / \mathrm{mol}, \mathrm{mp} 270-274{ }^{\circ} \mathrm{C}$, solubility $1 \mathrm{~g} / 120 \mathrm{~mL} \mathrm{H}_{2} \mathrm{O}(\mathrm{RT})$, purity $>98 \%$, Figure 1 , Sigma-Aldrich Chemie BV, Zwijndrecht, The Netherlands).

Hydroxylapatite (a nonsintered bonelike ceramic filler with an average particle size $<20 \mu \mathrm{m}$ ) was supplied by CAM Implants BV, Leiden, The Netherlands. All of the other reagents used in the experiments were of analytical grades.

Glyoxal was the selected cross-linker because of its dialdehyde functionality able to react with the free $\epsilon$-amine groups of the lysine (or hydroxylysine) residues of soy protein (eq 1):

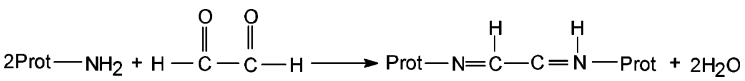

Moreover, glyoxal has shown to be less toxic for the human cells than the most commonly used formaldehyde and glutaraldehyde cross-linkers when used to cross-link proteinbased matrixes such as collagen. ${ }^{25}$

2.2. Premix Preparation. Premixes of the matrix material (soy protein isolate), filler, and drug were prepared prior to processing. The constituents of each formulation were weighed and transferred into a mixer container. This was followed by mixing all of the compounds for $15 \mathrm{~min}$ at room temperature $\left(25^{\circ} \mathrm{C}\right)$ using a Bear Varimixer (Bear, Denmark) equipped with a low-shear spiral-mixing tool at a speed of $45 \mathrm{rpm}$.

2.3. Melt Extrusion. The solid premixes were converted into plastic materials with encapsulated $\mathrm{TH}$ by extrusion. ${ }^{26}$ They were directly fed into a corotating twin-screw extruder (Berstorff, Hannover, Germany, $D=25 \mathrm{~mm}$ and $L=40 D$ ). The liquids, such as plasticizers (glycerol and water (or a buffer solution of acetic acid $\left(\mathrm{CH}_{3} \mathrm{COOH}\right) /$ sodium acetate $\left.\left(\mathrm{CH}_{3} \mathrm{COONa}\right) 200 \mathrm{mM}, \mathrm{pH} 4\right)$ ) and cross-linker (glyoxal), were concurrently injected into the second feeding zone of the extruder barrel with a piston pump (Pro Minet, Verder BV, The Netherlands). Table 1 presents all of the formulations prepared during this experiment and the respective codes. The following extrusion conditions, based on preliminary research work, were used: a screw speed of 200 rpm and a temperature profile of 50-70-80-80-80-80$80-80-80-50{ }^{\circ} \mathrm{C}$ (from the hoper to the die).

The obtained extrudates were cooled to room temperature and cut into pellets. Prior to further analysis they were dried for $24 \mathrm{~h}$ at $60{ }^{\circ} \mathrm{C}$.

2.4. Sample Preparation. Dumbbell-like specimens $(4 \times$ $10 \mathrm{~mm}^{2}$ of cross section) were injection-moulded in a DEMAG D25 NC IV machine under optimized and steady processing conditions, namely, barrel temperatures ranging from 120 to $140{ }^{\circ} \mathrm{C}$, injection pressure of $2500 \mathrm{bar}$, and 100 $\mathrm{mm} / \mathrm{s}$ injection speed during $5.0 \mathrm{~s}$ of injection time.

A batch of the injection-moulded specimens was subjected to a thermal treatment performed at $80^{\circ} \mathrm{C}$ during $24 \mathrm{~h}$ in an air-circulating oven (24TT-SID $\left.{ }_{\mathrm{tp}}\right)$. Subsequently, all of the specimens $\left(\mathrm{SID}_{\mathrm{tp}}, 0.6 \mathrm{X}-\mathrm{SID}_{\mathrm{tp}}, 24 \mathrm{TT}-\mathrm{SID}_{\mathrm{tp}}, \mathrm{SIpD}_{\mathrm{tp}}\right.$, and SI$\mathrm{HAD}_{\mathrm{tp}}$ ) were conditioned at $25^{\circ} \mathrm{C}$ and $60 \%$ relative humidity $(\mathrm{RH})$ for at least 1 week before testing (ISO 483:1998 (E)).

2.5. Sample Characterization. 2.5.1. Morphology. The mouldings morphology was assessed by observation of the respective sections (parallel to the flow direction) using an 
Biomacromolecules

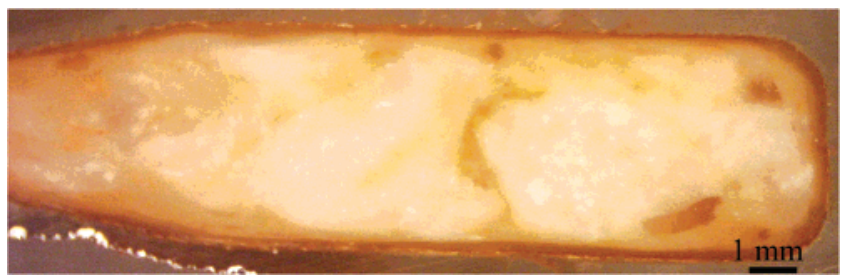

Figure 2. General $S I D_{\text {tp }}$ moulding morphology.

Olympus SZ-ET stereoscope magnifier. The respective photographs were taken using an Olympus DP 11 digital camera. Figure 2 illustrates a typical section of the moulding SID $_{\text {tp }}$ showing the utility of the production methodology to form homogeneous drug dispersions.

2.5.2. Cross-Linking Degree. The cross-linking degree of the produced specimens was evaluated through the quantification of the reduction of the respective free amine group content. This was determined using the OPA (o-phthaldialdehyde) method. ${ }^{27}$ A $50 \mu \mathrm{L}$ aliquot of a solution containing $2 \mathrm{~g} / \mathrm{L}$ of protein powder dissolved in sodium tetraborate buffer $(0.0125 \mathrm{M}+2 \%$ SDS $)$ was added directly to $1.0 \mathrm{~mL}$ of OPA reagent in a cuvette. The resulting solution was mixed rapidly and incubated for $2 \mathrm{~min}$ at room temperature before the absorbency was read at $340 \mathrm{~nm}$ against water. The determination of the free amine groups of each sample was achieved through a calibration curve previously established using L-leucine as a standard.

2.6. Drug Release Studies. The release kinetics of the model drug TH from the soy matrixes was also assessed. Randomly selected batches of specimens were immersed at $37{ }^{\circ} \mathrm{C}$ in isotonic saline solutions (ISS, $\mathrm{NaCl} 9 \mathrm{~g} / \mathrm{L}-1 \%$ sodium azide $\left(\mathrm{NaN}_{3}\right)$ ) buffered at two different $\mathrm{pHs:} \mathrm{(i)} \mathrm{pH}$ $5.0 \pm 0.03,0.2 \mathrm{M}$ acetic acid $\left(\mathrm{CH}_{3} \mathrm{CO}_{2} \mathrm{H}\right) / 0.2 \mathrm{M}$ sodium acetate $\left(\mathrm{CH}_{3} \mathrm{CO}_{2} \mathrm{Na}\right)$ buffer; (ii) $\mathrm{pH} 7.4 \pm 0.02,0.2 \mathrm{M}$ tris(hydroxymethyl) aminomethane/0.2 $\mathrm{M}$ hydrochloric acid ( $\mathrm{HCl})$ buffer $(0.2 \mathrm{M}$ Tris-HCl buffer). The $1 \%$ sodium azide was used to avoid the growth of unwanted microorganisms. The experiments were performed in a horizontal shaker (GFL 3033, Gesellschaft, Burgwedel, Germany) at $100 \mathrm{rpm}$.
Soy Matrix Drug Delivery Systems

At preset times, $1 \mathrm{~mL}$ of every solution was taken out 176 and replaced by $1 \mathrm{~mL}$ of fresh solution. The solution was then carefully filtered using a Microcon filter (Amicon, The Netherlands) of $10 \mathrm{kD}$ mesh. The supernatant was assayed for released of TH at $273 \mathrm{~nm}$ using an Alliance HPLC-UV system (Water Chromatography BV, The Netherlands) coupled with a Waters 2690 separations module and a Waters 996 photodiode array detector. The selected mobile phase corresponded to a mixture of water/acetronitrile $(80: 20 \mathrm{v} / \mathrm{v})$ used at a flow rate of $0.75 \mathrm{~mL} / \mathrm{min}$. A Chrompack Varian Hypersyl $5 \mu \mathrm{m}$ ODS column of $150 \mathrm{~mm} \times 4.6 \mathrm{~mm}$ was used in combination with a $1 \mathrm{~cm}$ precolumn. All experiments were conducted in triplicate.

The total drug loading of the samples was also determined using the above-described HPLC system. Ten milligrams of each sample, previously pulverized, were dissolved in 100 $\mathrm{mL}$ of ethanol. A $100 \mu \mathrm{L}$ aliquot of this solution was injected onto the column to determine the theophylline concentration. Using these data, we calculated the percentage of theophylline in the sample versus the theoretical concentration.

2.7. Solubility Determination. An excess amount of $\mathrm{TH}$ was placed in contact with ISS-acetate buffer, $\mathrm{pH}$ 5.0, and ISS-Tris/HCl buffer, $\mathrm{pH} 7.4$, to determine its solubility in these release media. The samples were shaken for $24 \mathrm{~h}$ at $37^{\circ} \mathrm{C}$. After convenient centrifugation, the supernatant was filtered through a $0.45 \mu \mathrm{m}$ syringe filter. Aliquots of the filtrate liquids were analyzed for TH by HPLC-UV as described previously (section 2.6).

2.8. Wet and Dry Weight Studies. Pure soy matrix (SI) specimens were immersed as described in section 2.6. They were weighed at time $t=0$ (initial weight). The bars were withdrawn from the release media (ISS-Tris/ $\mathrm{HCl}$ for $\mathrm{pH}$ 7.4 or ISS $-\mathrm{CH}_{3} \mathrm{COOH} / \mathrm{CH}_{3} \mathrm{COONa}$ for $\mathrm{pH} 5.0$ ) at predetermined time intervals. They were sequentially weighed in the wet state (wet weight) and dried to constant weight in a vacuum oven at $40{ }^{\circ} \mathrm{C}$ during $24 \mathrm{~h}$ (ISO 62:1980 (E)) (dry weight). All experiments were also performed in triplicate.

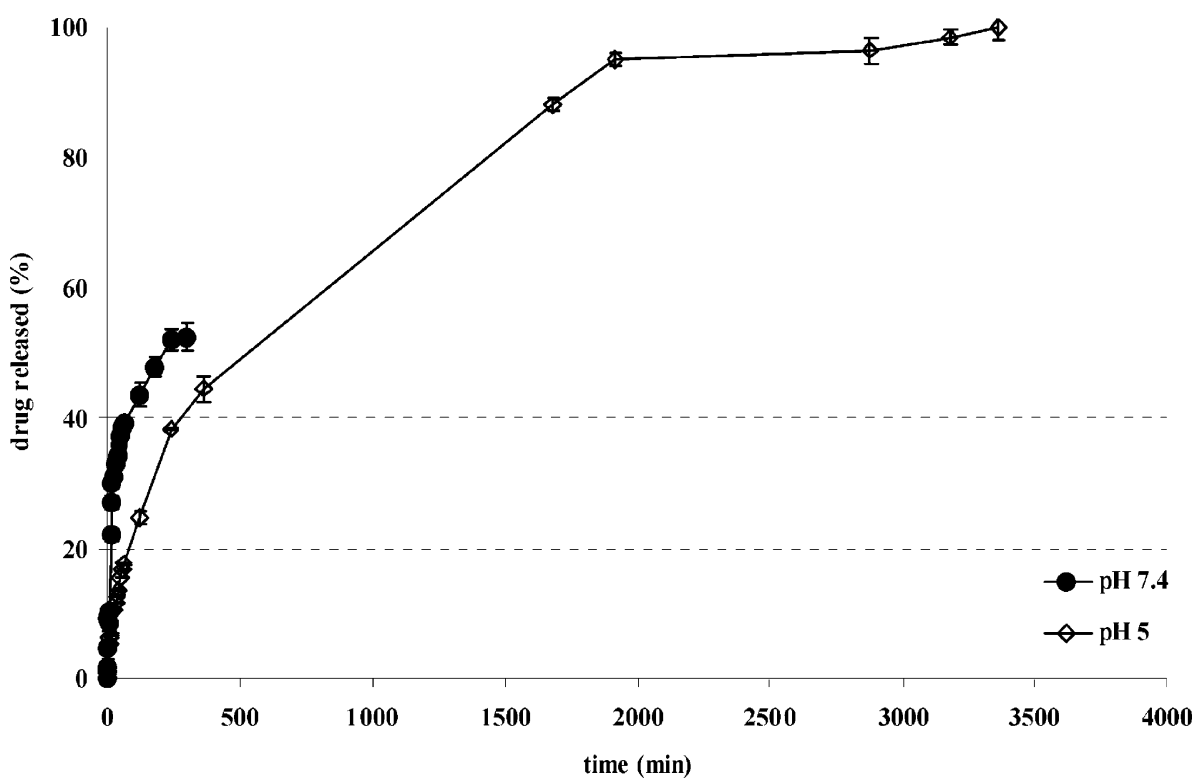

Figure 3. Release kinetics of theophylline from a soy matrix $\operatorname{SID}_{\mathrm{tp}}(\diamond)$ in an ISS-acetate buffer, $\mathrm{pH} 5.0$, and $(\bullet)$ in an ISS-Tris/HCI buffer, $\mathrm{pH}$ 7.4 (ISS = isotonic saline solution, $9 \mathrm{~g} / \mathrm{L} \mathrm{NaCl}-1 \%$ sodium azide $\left(\mathrm{NaN}_{3}\right)$ ). 
D Vaz et al.

Biomacromolecules

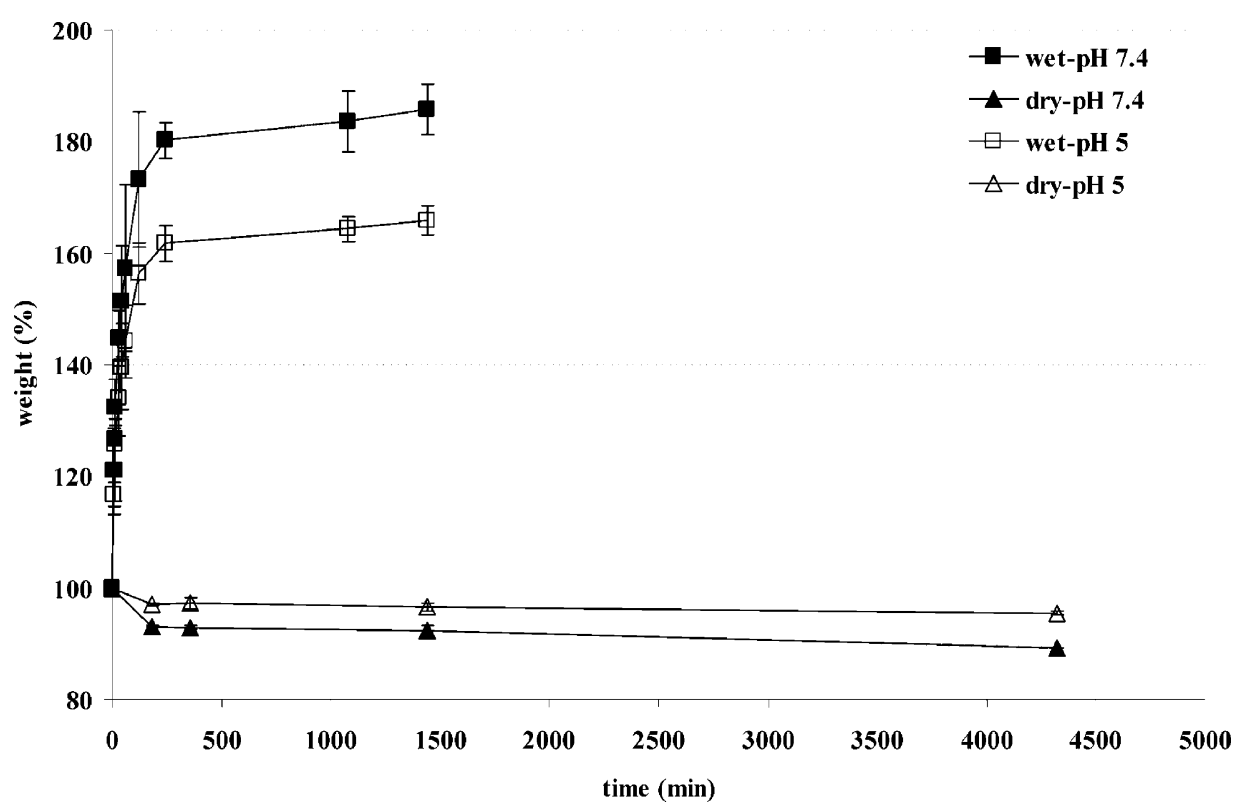

Figure 4. Dry and wet weight of a soy matrix $\operatorname{SID}_{\mathrm{tp}}$ versus time $(\triangle, \square)$ in an ISS-acetate buffer, pH 5.0, and $(\boldsymbol{\Lambda}, \boldsymbol{\square})$ in an ISS-Tris/HCI buffer, $\mathrm{pH} 7.4$ (ISS = isotonic saline solution, $9 \mathrm{~g} / \mathrm{L} \mathrm{NaCl}-1 \%$ sodium azide $\left(\mathrm{NaN}_{3}\right)$ ).

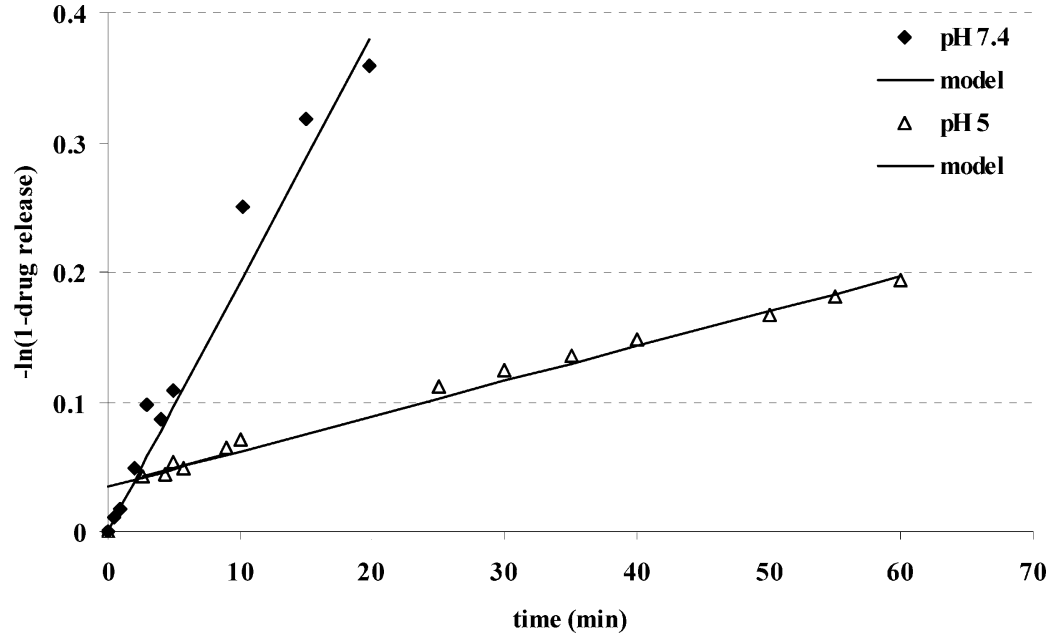

Figure 5. Modeling theophylline release from a soy matrix $\operatorname{SID}_{\mathrm{tp}}(\triangle)$ in an ISS-acetate buffer, $\mathrm{pH} 5.0$, and $(\bullet)$ in a ISS-Tris/HCI buffer, $\mathrm{pH} 7.4$ (ISS = isotonic saline solution, $9 \mathrm{~g} / \mathrm{L} \mathrm{NaCl}-1 \%$ sodium azide $\left(\mathrm{NaN}_{3}\right)$ ). Fit of the pure diffusion model (considering drug transport only with constant diffusivity and stationary boundary conditions) to experiments is shown.

2.9. Release Kinetics. Assuming perfect sink conditions, homogeneous initial drug distribution, and constant diffusivity and considering only drug diffusion, the diffusion process for specimens with rectangular parallelepipedgeometry and composed of materials following the Fick's second law can be described by eq $2::^{28}$

$$
\begin{aligned}
& \frac{M_{t}}{M_{\infty}}=1-\frac{512}{\pi^{6}} \sum_{m=0}^{\infty} \frac{1}{(2 m+1)^{2}} \times \\
& \quad \exp \left(-\frac{(2 m+1)^{2} \pi^{2}}{a_{\mathrm{p}}^{2}} D t\right) \sum_{n=0}^{\infty} \frac{1}{(2 n+1)^{2}} \times \\
& \exp \left(-\frac{(2 n+1)^{2} \pi^{2}}{b_{\mathrm{p}}{ }^{2}} D t\right) \sum_{p=0}^{\infty} \frac{1}{(2 p+1)^{2}} \exp \left(-\frac{(2 p+1)^{2} \pi^{2}}{c_{\mathrm{p}}{ }^{2}} D t\right)
\end{aligned}
$$

where $D$ is diffusion coefficient of the drug, $M_{t}$ and $M_{\infty}$ are the amount of drug released at time $t$ and $t=\infty$, respectively,
Table 2. Apparent Drug Diffusion Coefficients, $D$, Predicted Using $M_{\mathrm{t}} / M_{\infty}=1-\exp \left(-\left(8 / R_{\mathrm{c}}{ }^{2}\right) D t\right)^{a}$

\begin{tabular}{llllll}
\hline & \multicolumn{5}{c}{ apparent diffusion coefficient, $D \times 10^{-5}\left(\mathrm{~cm}^{2} / \mathrm{min}\right)$} \\
\cline { 2 - 6 } $\mathrm{pH}$ & \multicolumn{1}{c}{$\mathrm{SID}_{\mathrm{tp}}$} & $0.6 \mathrm{X}-\mathrm{SID}_{\mathrm{tp}}$ & $24 \mathrm{TT}-\mathrm{SID}_{\mathrm{tp}}{ }^{b}$ & \multicolumn{1}{c}{$\mathrm{SIpD}_{\mathrm{tp}}$} & $\mathrm{SI}-\mathrm{HAD}_{\mathrm{tp}}$ \\
\hline 5.0 & $4.29 \pm 0.02$ & $2.86 \pm 0.02$ & $2.54 \pm 0.01$ & $3.17 \pm 0.02$ & $2.54 \pm 0.04$ \\
7.4 & $30.5 \pm 0.4$ & $12.4 \pm 0.1$ & $12.9 \pm 0.1$ & $21.3 \pm 0.1$ & $37.5 \pm 0.3$
\end{tabular}

abbreviations: SID $_{t p}$, thermoplastic soy matrix with encapsulated theophylline; $0.6 \mathrm{X}-\mathrm{SID}_{\mathrm{tp}}$, glyoxal cross-linked thermoplastic soy matrix with encapsulated theophylline; $24 T T-S I D_{t p}$, thermal-treated thermoplastic soy matrix with encapsulated theophylline; $\mathrm{SIpD}_{\mathrm{tp}}$, thermoplastic soy matrix with encapsulated theophylline extruded at $\mathrm{pH} 4$; SI-HAD $\mathrm{tp}_{\mathrm{tp}}$, hydroxylapatite-reinforced thermoplastic soy matrix with encapsulated theophylline. ${ }^{b}$ Subjected to thermal treatment, $24 \mathrm{hrs} / 80^{\circ} \mathrm{C}$.

and $a_{\mathrm{p}}, b_{\mathrm{p}}$, and $c_{\mathrm{p}}$ denote the rectangular parallelepiped 221 lengths along the $x$-, $y$ - and $z$-axes, respectively. In the present 222 studied case, $a_{\mathrm{p}}=10 \mathrm{~mm}, b_{\mathrm{p}}=14 a_{\mathrm{p}}$, and $c_{\mathrm{p}}=a_{\mathrm{p}} / 2.5$. 223

To simplify eq 2 , the rectangular cross sections of the 224 rectangular parallelepiped specimens were converted into 225 circular cross sections (cylindrical specimen). This correction 226 was based on the hydraulic radius concept $\left(R_{\mathrm{c}}=227\right.$ $\left.\sqrt{\left(a_{\mathrm{p}} c_{\mathrm{p}} / \pi\right)}\right)$. 

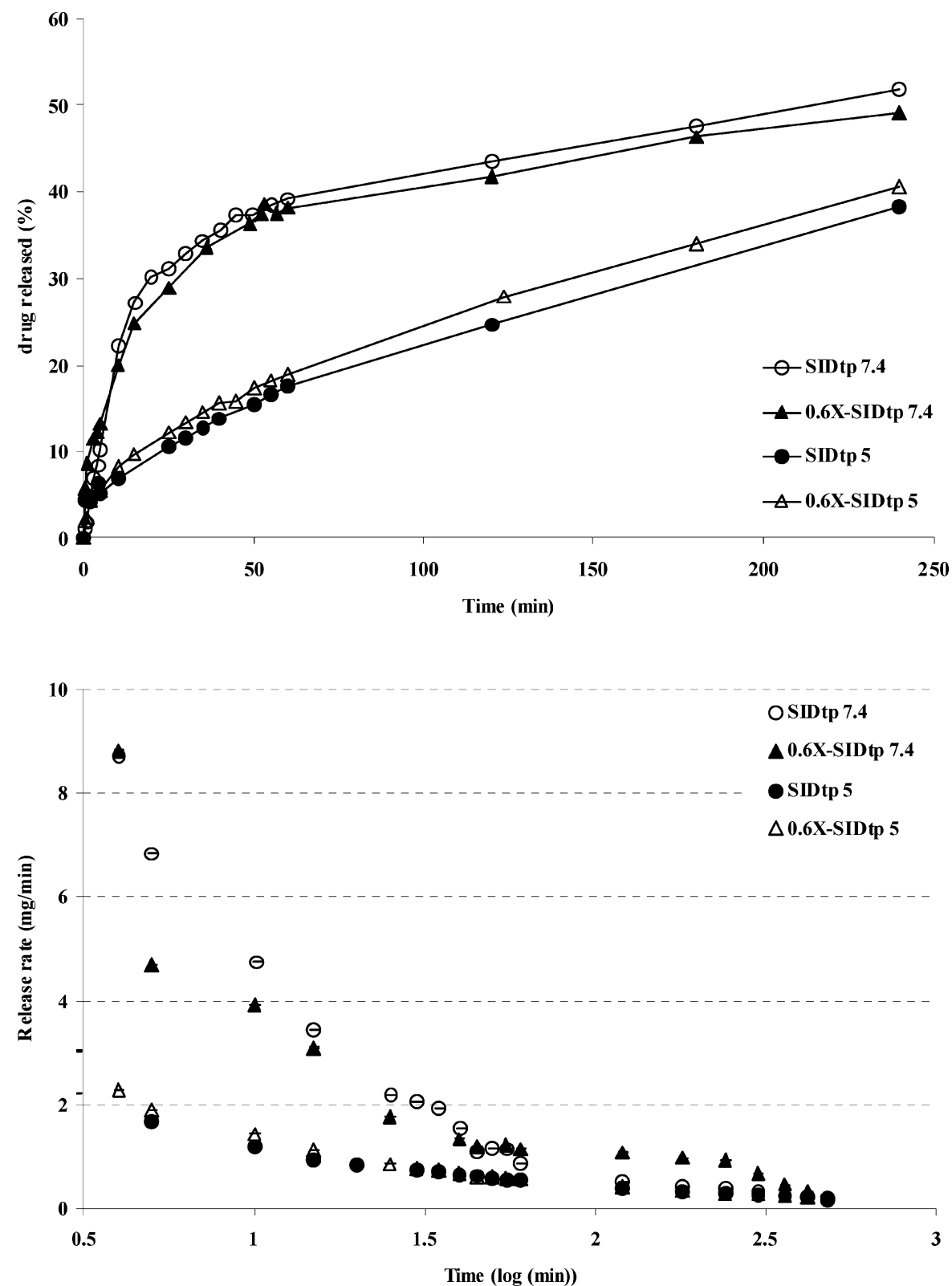

Figure 6. Effect of the difference of cross-linking degree of the amine groups between the matrixes $S I D_{t p}$ and $0.6 X-S I D_{t p}$ on (a) theophylline drug release kinetics and (b) theophylline release rates when immersed in an ISS-acetate buffer, $\mathrm{pH} 5.0$, and in an ISS-Tris/HCl buffer, $\mathrm{pH}$ 7.4 (ISS = isotonic saline solution, $9 \mathrm{~g} / \mathrm{L} \mathrm{NaCl}-1 \%$ sodium azide $\left.\left(\mathrm{NaN}_{3}\right)\right)$. SDs were within \pm 0.05 in all cases.

Taking into account radial, as well as axial, mass transfer, the cumulative amount of drug released versus time for the cylinder of radius $R_{\mathrm{c}}$ and height $H_{\mathrm{c}}\left(H_{\mathrm{c}}=b_{\mathrm{p}}\right)$ is given by eq $3:^{28}$

$$
\begin{aligned}
& \frac{M_{\mathrm{t}}}{M_{\infty}}=1-\frac{32}{\pi^{2}} \sum_{v=1}^{\infty} \frac{1}{q_{v}^{2}} \times \\
& \exp \left(-\frac{q_{v}^{2}}{R_{\mathrm{c}}^{2}} D t\right) \sum_{n=0}^{\infty} \frac{1}{(2 n+1)^{2}} \exp \left(-\frac{(2 n+1)^{2} \pi^{2}}{H_{\mathrm{c}}{ }^{2}} D t\right)
\end{aligned}
$$

where $q_{v}$ are the roots of the Bessel function of the first kind of order zero (eq 4): ${ }^{28}$

$$
J_{0}\left(q_{v}\right)=0
$$

Because the ratio height/radius is higher than $10,{ }^{28} \mathrm{a}$ simplification concerning the dimensionality of the problem is possible: the axial mass transfer in the cylinder can be 237 negligible compared with the radial mass transfer. Conse- 238 quently, eq 3 can be approximated by eq $5:^{28}$

$$
\frac{M_{\mathrm{t}}}{M_{\infty}}=1-4 \sum_{n=1}^{\infty} \frac{1}{q_{v}{ }^{2}} \exp \left(-\frac{q_{v}{ }^{2}}{R_{\mathrm{c}}{ }^{2}} D t\right)
$$

Equation 5 can be solved for the Bessel function of first type, 240 zero order, and four roots $(v=4)$

$$
J_{0}(q)=1-\frac{q^{2}}{4}+\frac{q^{4}}{64}=0
$$

resulting in the following expression:

$$
\frac{M_{\mathrm{t}}}{M_{\infty}}=1-\exp \left(-\frac{8}{R_{\mathrm{c}}^{2}} D t\right)
$$


F Vaz et al.

Biomacromolecules
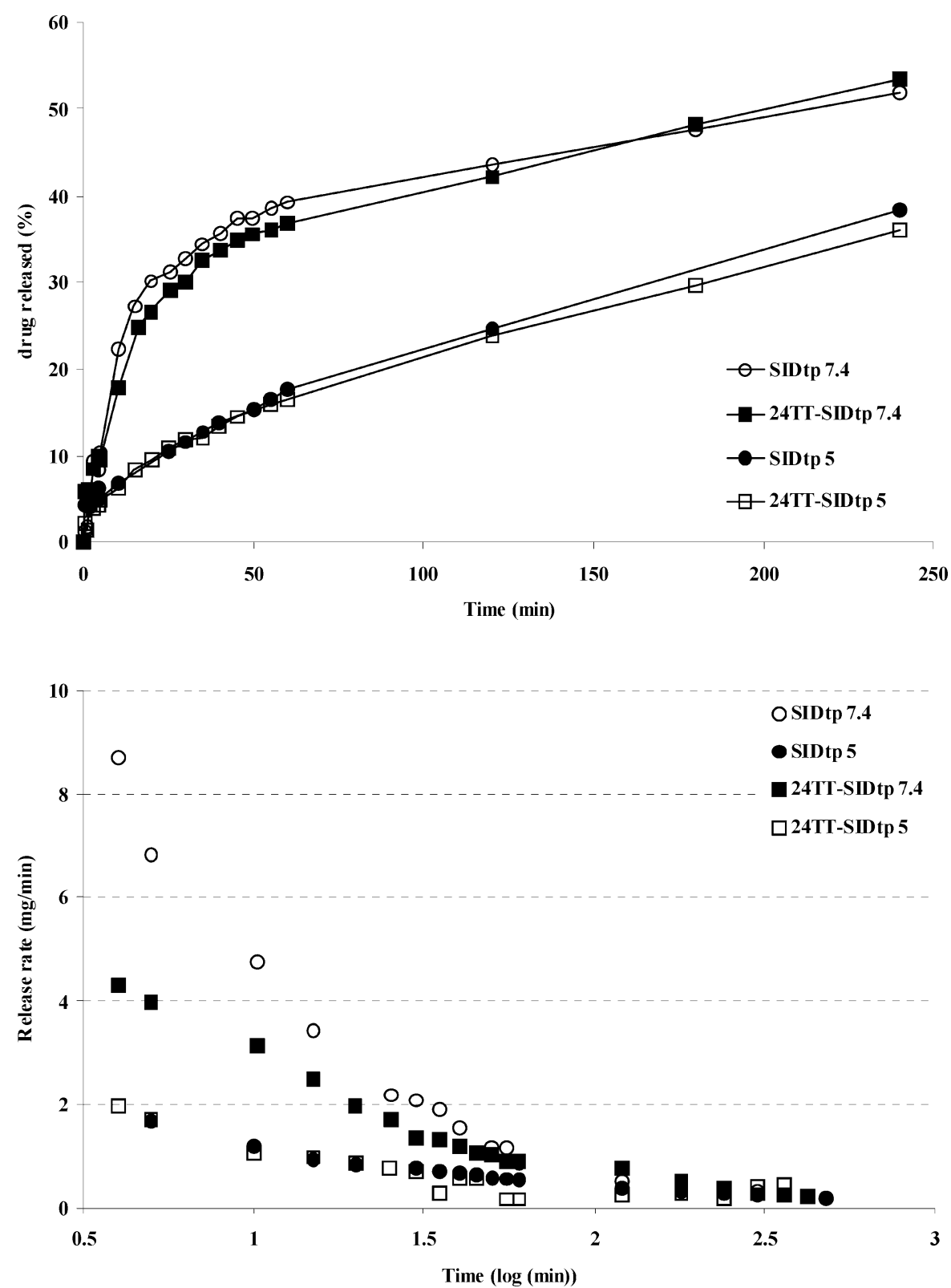

Figure 7. Effect of difference in cross-linking degree due to thermal treatment between the matrixes $S_{\text {tp }}$ and $24 T T$-SID $D_{t p}$ on (a) theophylline drug release kinetics and (b) theophylline release rates when immersed in an ISS-acetate buffer, $\mathrm{pH} 5.0$, and in an ISS-Tris/HCl buffer, pH 7.4 (ISS = isotonic saline solution, $9 \mathrm{~g} / \mathrm{L} \mathrm{NaCl}-1 \%$ sodium azide $\left.\left(\mathrm{NaN}_{3}\right)\right)$. SDs were within \pm 0.10 in all cases.

The release data obtained for all of the soy matrixes were compared with predictions of the above-described equation.

\section{Results and Discussion}

\subsection{Drug Release from Soy Matrix with Encapsulated} TH (SID tp $_{\text {) }}$. Figure 3 illustrates the pH-dependent release of TH from the soy matrix $\mathrm{SID}_{\mathrm{tp}}$ in the two solutions used: ISS - acetate buffer, $\mathrm{pH} 5.0$, and ISS-Tris/HCl buffer, $\mathrm{pH}$ 7.4. In ISS-acetate buffer, $\mathrm{pH}$ 5.0, the drug was completely released within a $56 \mathrm{~h}$ time period. However, with ISSTris/ $\mathrm{HCl}$ buffer, $\mathrm{pH} 7.4$, the maximum release was $52 \%$, reached immediately after $4 \mathrm{~h}$ of immersion. This difference in maximum release was attributed to the amphoteric nature of the polymer. Soy is almost insoluble at $\mathrm{pH} 5.0$ because its net charge is approximately zero (isoelectric point of soy is 4.3-4.8). Consequently, polymer-drug interactions tend to be minimal, and the maximum release can reach $100 \%$. In contrast, at $\mathrm{pH} 7.4$ the net charge is negative. So, it is expected that the $\mathrm{TH}$ is linked (or interacts) with the negatively charged polymer matrix, inhibiting the respective release process ( $48 \%$ nonreleased material). This difference in the release rates can also be related with the coefficient of diffusion of the TH for the two different $\mathrm{pHs}$ because the drug solubility in both media is similar: $22.0 \pm 0.5$ and 18.9 $\pm 0.8 \mathrm{mg} / \mathrm{mL}$ at $\mathrm{pH} 7.4$ and 5.0 , respectively.

The behavior of the pure polymer used as a matrix (SI) within both release media was also examined, including its swelling and weight loss profiles. The changes in dry and wet weight of SI bars in ISS-acetate buffer, $\mathrm{pH}$ 5.0, and in ISS-Tris/HCl buffer, $\mathrm{pH} 7.4$, are plotted against time in Figure 4. As expected, at lower pH the SI dry weight remained nearly constant because the polymer solubility under these conditions is low. Interestingly, the water uptake 

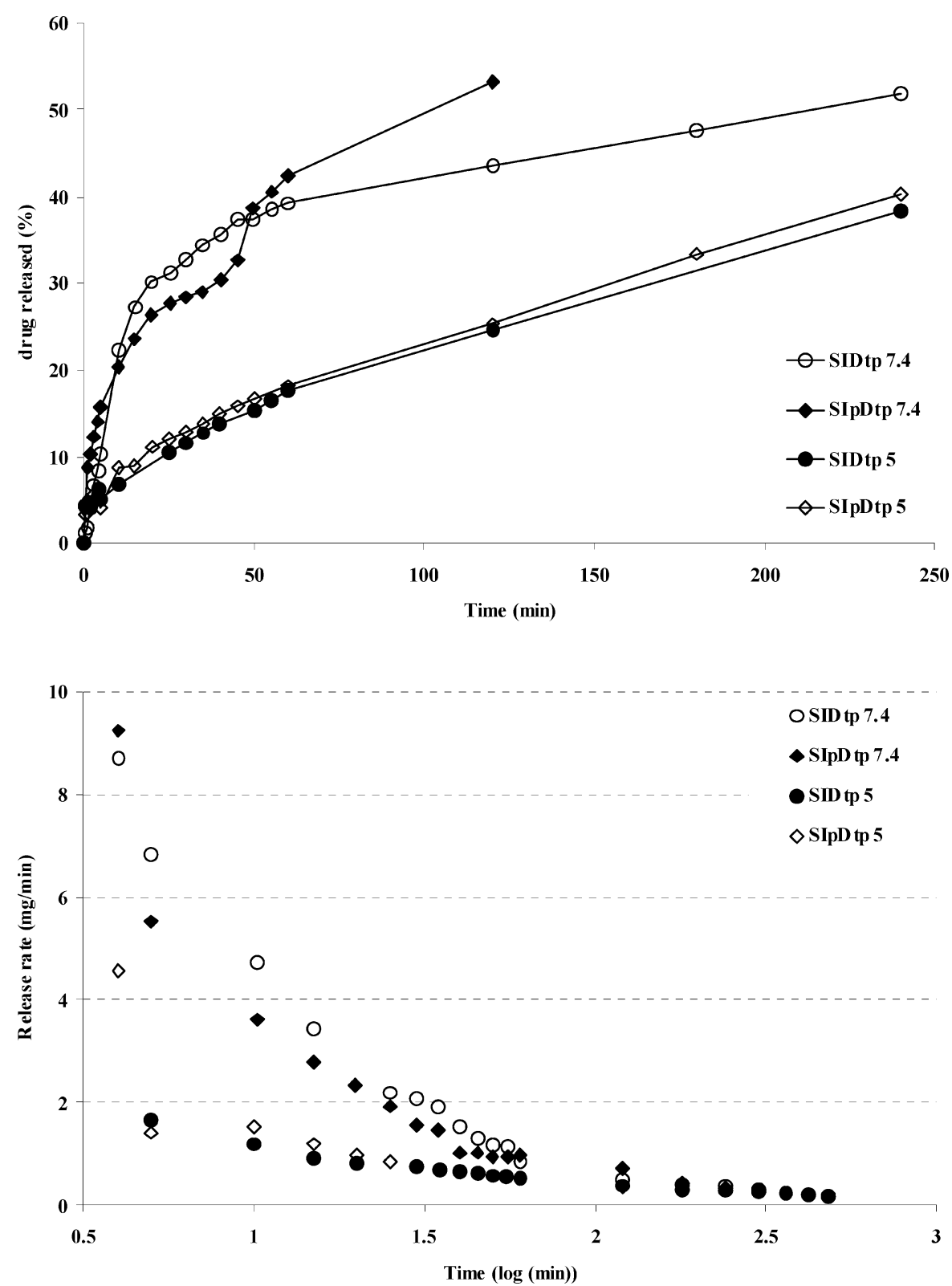

Figure 8. Effect of the differences in net charge between the matrixes $S I D_{t p}$ and $S I p D_{t p}$ on (a) theophylline drug release kinetics and (b) theophylline release rates when immersed in an ISS-acetate buffer, $\mathrm{pH} 5.0$, and in an ISS-Tris/ $\mathrm{HCl}$ buffer, $\mathrm{pH} 7.4$ (ISS = isotonic saline solution, $9 \mathrm{~g} / \mathrm{L} \mathrm{NaCl}-1 \%$ sodium azide $\left.\left(\mathrm{NaN}_{3}\right)\right)$. SDs were within \pm 0.15 in all cases.

rate was high, reaching equilibrium at both pHs after $4 \mathrm{~h}$ of immersion. In addition, the volume of the matrixes remained almost constant during this time period. Therefore, because perfect sink conditions were assured during drug release, stationary boundary conditions can be considered to describe the drug diffusion process.

As it can be observed from Figures 2 and 3, at pH 5 water uptake is fast compared with drug diffusion. Pure SI matrixes are saturated within $4 \mathrm{~h}$, whereas drug release does not exceed $38 \%$ after this time. Thus, the drug diffusivity can be assumed to be constant and equal to the diffusivity in the fully wetted system.

Conversely, at pH 7.4 water uptake is synchronized with the drug diffusion. Pure SI matrixes are fully wetted within $4 \mathrm{~h}$, the time necessary for the complete drug diffusion. Accordingly, the diffusivity of the drug is dependent on the buffer diffusion through the matrix.
Under these conditions and considering the initial homogeneous distribution of the drug through the specimen, the Fick's second law (eq 2) can be approximated by the analytical solutions described by eq 7 . Figure 5 shows the fits of eq 7 to the experimentally determined drug release data. Good agreement was achieved when the release was performed at $\mathrm{pH} 5$, indicating the validity of this model for this system $\left(r^{2}=0.9893\right)$. The apparent diffusion coefficient of theophylline in the ISS-acetate buffer, $\mathrm{pH} 5.0$, wetted soy matrix was determined assuming a value of $4.29 \times 10^{-5}$ $\mathrm{cm}^{2} /$ min (Table 2). Not as good agreement was found for the studies performed at $\mathrm{pH} 7.4\left(r^{2}=0.9755\right)$. This is mainly due to the time-variant matrix structure, nonconstant drug diffusivities, and dependence of drug diffusivity on the buffer diffusivity. Nevertheless, the apparent diffusion coefficient of theophylline in the ISS-Tris/ $\mathrm{HCl}$ buffer, $\mathrm{pH} 7.4$, wetted soy matrix was estimated $\left(3.05 \times 10^{-4} \mathrm{~cm}^{2} / \mathrm{min}\right.$, Table 2$) . \quad 308$ 

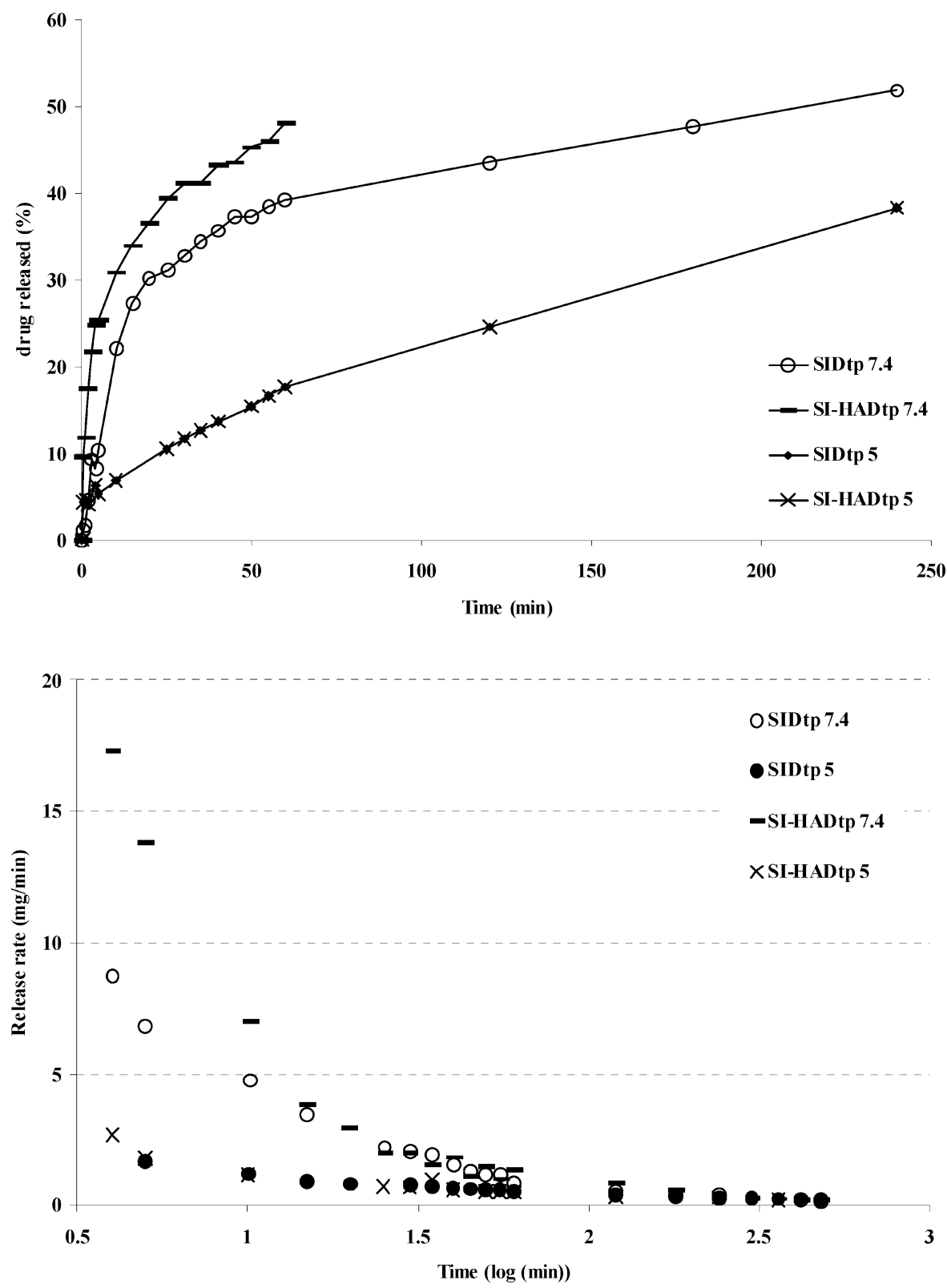

Figure 9. Effect of the differences in percentage of matrix reinforcement between the matrixes $S_{\text {tp }}$ and $S I-H A D_{t p}$ on (a) theophylline drug release kinetics and (b) theophylline release rates when immersed in an ISS-acetate buffer, $\mathrm{pH}$ 5.0, and in an ISS-Tris/HCI buffer, pH 7.4 (ISS $=$ isotonic saline solution, $9 \mathrm{~g} / \mathrm{L} \mathrm{NaCl}-1 \%$ sodium azide $\left.\left(\mathrm{NaN}_{3}\right)\right)$. SDs were within \pm 0.15 in all cases.

In conclusion, drug release from SID $_{\text {tp }}$ bars in ISS - acetate buffer ( $\mathrm{pH}$ 5.0) is purely drug-diffusion-controlled, whereas in ISS-Tris/HCl buffer ( $\mathrm{pH} 7.4$ ), the water uptake kinetics have to be taken in consideration.

3.2. Influence of Formulation. 3.2.1. Cross-Linking Degree. Figures 6A and 7A show the effect of the crosslinking degree on the resulting drug release rate. Increasing the amine group cross-linking degree from $2.5 \%\left(\mathrm{SID}_{\mathrm{tp}}\right)$ to $27.8 \%\left(24 \mathrm{TT}-\mathrm{SID}_{\mathrm{tp}}\right)$ and to $44.1 \%\left(0.6 \mathrm{X}-\mathrm{SID}_{\mathrm{tp}}\right)($ Table 1$)$ causes a reduction of the $\mathrm{TH}$ release rate in $\mathrm{ISS}-\mathrm{Tris} / \mathrm{HCl}$ buffer, $\mathrm{pH}$ 7.4. This can be attributed to differences in the matrix structure. At high $\mathrm{pH}$, a less-cross-linked polymer matrix allows drug diffusion more efficiently than a more tightly cross-linked structure, leading to increased diffusion rates (Table 2). At pH 7.4, a $42 \%$ cross-linking degree (0.6X$\mathrm{SID}_{\mathrm{tp}}$ ) (Table 1) resulted in about $60 \%$ reduction of the apparent diffusion coefficient (Table 2), when compared with the non-cross-linked material.

The thermal-treated matrixes proved to promote a more effective reduction in the drug release rate. In fact, a $25 \%$ cross-linking degree $\left(24 \mathrm{TT}-\mathrm{SID}_{\mathrm{tp}}\right.$, Table 1$)$ directs a reduction of the apparent diffusion coefficient (Table 2) of about $60 \%$ (at $\mathrm{pH}$ 7.4) when compared with SID $_{\text {tp. This behavior can }}$ be explained by the two different types of cross-linking that may coexist in the soy material: (i) reaction with the amine groups of lysine (or hydroxylysine) residues $(27.8 \%$ crosslinking, Table 1) and (ii) formation of disulfide bonds by oxidation of the thiol groups of cysteine residues (maximum $30 \%$ cross-linking through cysteine residues, eq 8).

$$
2 \text { Prot }-\mathrm{SH} \stackrel{[\mathrm{O}]}{\rightleftharpoons} \text { Prot }-\mathrm{S}-\mathrm{S}-\text { Prot }
$$

However, at low $\mathrm{pH}$ values (ISS-acetate buffer, $\mathrm{pH} 5$ ), the 338 
matrixes are fairly soluble; thus, the drug diffusion rates are slower and almost independent of the degree of cross-linking of the matrix. Nevertheless, at $\mathrm{pH} 7.4$, increasing the crosslinking degree of the polymer matrix is a possible route to adjust the system to the individual needs of the drug. Depending on the pharmacokinetics of the drug to be administered, this effect might be more or less important.

3.2.2. Net Charge. Because the isoelectric point of soy ranges between $\mathrm{pH} 4.2$ and 4.8 , the extrusion performed at $\mathrm{pH} 4.0$ (formulation 4) was intended to produce matrixes with a net charge lower than that obtained using water as a plasticizer $(\mathrm{pH} \approx 6.8)$. In general, the release rates of $\mathrm{SIpD}_{\mathrm{tp}}$ and $\mathrm{SID}_{\mathrm{tp}}$ were rather similar both in ISS-acetate buffer, $\mathrm{pH}$ 5.0, and ISS-Tris/HCl buffer, pH 7.4 (Figure 8A). However, at high $\mathrm{pH}$, the total release for $\mathrm{SIpD}_{\mathrm{tp}}$ is smaller than that for $\operatorname{SID}_{\mathrm{tp}}$ (Figure 8B). This effect must be related to the leaching of acetic acid from the sample and consequent reduction of the dissolution medium $\mathrm{pH}$ during the release tests.

3.2.3. Matrix Reinforcement. The addition of $30 \%$ of hydroxylapatite to the matrix led to a significant acceleration of drug release in ISS-Tris/HCl buffer, $\mathrm{pH} 7.4$ (Figure 9A,B and Table 2). This can be attributed to the lack of polymerreinforcement interactions in these composites. ${ }^{26}$ Therefore, the drug will easily diffuse through the open polymerceramic interfacial regions and be released out of the matrix. At low $\mathrm{pH}$, no significant differences in the release rates were found.

Thus, the choice of the appropriate type of matrix is an important point in determining the performance of the drugmatrix system. Depending on the type of drug and desired release profile, the matrix bulk material has to be carefully selected.

\section{Conclusions}

A new type of polymeric matrix that can be used in controlled release applications has been developed using melt-based processing techniques, such as extrusion and injection moulding. This two-step route allows for the encapsulation of a drug and the production of a moulded part without any subsequent finishing operations. The major advantages of these systems are as follows: (i) ease of production (especially at industrial scale); (ii) suitability for a large variety of polymeric matrixes; (iii) applicability to different types of drugs; (iv) biodegradability. The in situ modification of the matrix during processing by cross-linking, changing of net charge, or filler reinforcement appeared to be possible ways to adjust the material release patterns. Further, these new protein matrixes showed a $\mathrm{pH}$-sensitive behavior, which increases their possibility for application as controlled delivery devices to carry a range of bioactive agents.

Acknowledgment. Cláudia M. Vaz acknowledges the Portuguese Foundation for Science and Technology (FCT), Ministry of Science and Technology, Portugal, for the attribution of a PRAXIS XXI PhD scholarship.

\section{References and Notes}

(1) Choi, H.-G.; Jung, J.-H.; Yong, C. S.; Rhee, C.-D.; Lee, M.-K.; Han, J.-H.; Park, K.-M.; Kim, C.-K. Formulation and in vivo evaluation of omeprazole buccal adhesive tablet. J. Controlled Release 2000, 68, 405-412.

(2) Macleod, G. S.; Fell, J. T.; Collett, J. H. An in vitro investigation into the potential for bimodal drug release from pectin/chitosan/ HPMC-coated tablets. Int. J. Pharm. 1999, 188, 11-18.

(3) Castellano, I.; Goni, I.; Ferrero, M. C.; Munoz, A.; JimenezCastellanos, R.; Gurruchaga, M. Synthetic PMMA-grafted polysaccharides as hydrophilic matrix for controlled-release forms. Drug Dev. Ind. Pharm. 1999, 25 (12), 1249-1257.

(4) Fassihi, A.; Parker, M. Controlled drug release from a compressed heterogeneous polymeric matrix: kinetics of release. Drug Dev. Ind. Pharm. 1986, 12, 1649-1661.

(5) Fassihi, A.; Parker, M.; Pourkavous, N. Solid dispersion controlled release: effect of particle size, compression force and temperature. Drug Dev. Ind. Pharm. 1985, 11, 523-535.

(6) Said, S.; Al-Shora, H. Sustained release from inert matrixes. I. Effect of microcrystalline cellulose on aminophylline and theophylline release. Int. J. Pharm. 1980, 6, 11-18.

(7) Agabeyoglu, I. Studies on sustained release. I: The biopharmaceutical design and production of an inert matrix type sulphamethizole tablet employing polymethylmethacrylate. Drug Dev. Ind. Pharm. 1985, 11, 2021-2041.

(8) Flanders, P.; Dyer, G.A.; Jordan, D. The control of drug release from conventional melt granulation matrixes. Drug Dev. Ind. Pharm. 1987, $13,1001-1022$.

(9) McTaggart, C.; Canley, J.; Sickmueller, A.; Walker, J. The evaluation of formulation and processing conditions of a melt granulation process. Int. J. Pharm. 1984, 19, 139-148.

(10) Broman, E.; Khoo, C.; Taylor, L.S. A comparison of alternative polymer excipients and processing methods for making solid dispersions of a poorly water soluble drug. Int. J. Pharm. 2001, 222 (1), 139- 151 .

(11) Zhou, F.; Vervaet, C.; Schelkens, M.; Lefebvre, R.; Remon, J. P. Bioavailability of ibuprofen from matrix pellets based on the combination of waxes and starch derivatives. Int. J. Pharm. 1998, 168, 79-84.

(12) Onay-Basaran, S.; Olsen, J. Formulation of long-acting quinacrin hydrochloride pellets in different matrixes. Drug Dev. Ind. Pharm. 1985, 11 (12), 2143-2154.

(13) Henrist, D.; Remon, J. P. Influence of formulation composition on the in vitro characteristics of hot stage extrudates. Int. J. Pharm. 1999, $188,11-119$.

(14) Sprockel, O. L.; Sen, M.; Shivanand, P.; Prapaitrakul, W. A meltextrusion process for manufacturing matrix drug delivery systems. Int. J. Pharm. 1997, 155, 191-199.

(15) Yilmaz, G.; Jongboom, R.; Feil, H.; Hennink, W. E. Modulated release of a volatile compound from starch matrixes. Biomacromolecules 2002, 3 (2), 305-311.

(16) Seal, R. Industrial soya protein technology. In Applied protein chemistry; Grant, R. A., ed.; Applied Science Publishers Ltd: London, 1980; pp 87-112.

(17) Ferreira, S. H. P.; Arêas, J. A. G. Protein-protein interactions in the extrusion of soya at various temperatures and moisture contents. J. Food Sci. 1993, 58, 378-381.

(18) Silva, G. A.; Vaz, C. M.; Coutinho, O. P.; Cunha, A. M.; Reis, R. L. In vitro degradation and cytocompatibility of novel soy and sodiumcaseinate-based membrane biomaterials. J. Mater. Sci. Mater. Med., submitted for publication, 2003.

(19) Otaigbe, J. U.; Adams, D. O. Bioabsorbable soy protein plastic composites: Effect of polyphosphate fillers on water absorption and mechanical properties. J. Environ. Polym. Degrad. 1997, 5 (4), 199208.

(20) Paetau, I.; Chen, C.-Z.; Jane, J. Biodegradable plastic made from soybean products. II. Effects of cross-linking and cellulose incorporation on the mechanical properties and water absorption. J. Environ. Polym. Degrad. 1994, 2 (3), 211-217.

(21) Paetau, I.; Chen, C.-Z.; Jane, J. Biodegradable plastics made from soybean products. 1. Effects of preparation and processing on mechanical properties and water absorption. Ind. Eng. Chem. Res. 1994, 33, 1821-1827.

(22) Miyazaki, K. Availability of soy isoflavones and fermented soy products in foods and cosmetics. Foods Food Ingredients J. Jpn. 2002, 204, 1. 
(23) Vaz, C. M.; Fossen, M.; van Tuil, R. F.; de Graaf, L. A.; Reis, R. L.; Cunha, A. M. Mechanical, dynamic-mechanical and thermal properties of soy protein-based thermoplastics with potential biomedical applications. J. Macromol. Sci. Phys. 2002, B41, 33-46.

(24) Vaz, C. M.; de Graaf, L. A.; Reis, R. L.; Cunha, A. M. Soy proteinbased systems for different tissue regeneration applications. In Polymer Based Systems on Tissue Engineering, Replacement and Regeneration, vol. 86; Reis, R. L., Cohn, D., Eds.; Kluwer Academic Publishers: Dordrecht, The Netherlands, 2003; pp 86, 93-110.

(25) Weadock, K.; Olson, R. M.; Silver, F. H. Evaluation of collagen cross-linking techniques. Biomater., Med. Devices, Artif. Organs 1983, 11, 293-318.
(26) Vaz, C. M.; Fossen, M.; van Tuil, R. F.; de Graaf, L. A.; Reis, R. 482 L.; Cunha, A. M. Casein and soybean protein-based thermoplastics 483 and composites as alternative biodegradable polymers for biomedical $\quad 484$ applications. J. Biomed. Mater. Res., in press.

(27) Bertrand-Harb, C.; Nicolas, M.-G.; Dalgalarrondo, M.; Chobert, J.- 486 M. Determination of alkylation degree by three colorimetric methods 487 and amino acid analysis. A comparative study. Sci. Aliments 1993, 488 13, 577-584.

(28) Crank, J. Mathematics of Diffusion; Claredon Press: Oxford, U.K., 490 1975.

BM034050I 